Invited review

\title{
Electrical stimulation for the treatment of lower urinary tract dysfunction after spinal cord injury
}

\section{Meredith J. McGee ${ }^{1}$, Cindy L. Amundsen²,3, Warren M. Grill1,3,4,5}

${ }^{1}$ Department of Biomedical Engineering, Duke University, Durham, NC, USA, ${ }^{2}$ Department of Obstetrics and Gynecology: Division of Urogynecology and Reconstructive Pelvic Surgery, Duke University Medical Center, Durham, NC, USA, ${ }^{3}$ Department of Surgery: Division of Urology, Duke University Medical Center, Durham, NC, USA, ${ }^{4}$ Department of Electrical and Computer Engineering, Duke University, Durham, NC, USA, ${ }^{5}$ Department of Neurobiology, Duke University, Durham, NC, USA

Electrical stimulation for bladder control is an alternative to traditional methods of treating neurogenic lower urinary tract dysfunction (NLUTD) resulting from spinal cord injury (SCl). In this review, we systematically discuss the neurophysiology of bladder dysfunction following $\mathrm{SCl}$ and the applications of electrical stimulation for bladder control following SCl, spanning from historic clinical approaches to recent pre-clinical studies that offer promising new strategies that may improve the feasibility and success of electrical stimulation therapy in patients with SCI. Electrical stimulation provides a unique opportunity to control bladder function by exploiting neural control mechanisms. Our understanding of the applications and limitations of electrical stimulation for bladder control has improved due to many pre-clinical studies performed in animals and translational clinical studies. Techniques that have emerged as possible opportunities to control bladder function include pudendal nerve stimulation and novel methods of stimulation, such as high frequency nerve block. Further development of novel applications of electrical stimulation will drive progress towards effective therapy for SCl. The optimal solution for restoration of bladder control may encompass a combination of efficient, targeted electrical stimulation, possibly at multiple locations, and pharmacological treatment to enhance symptom control.

Keywords: Neurogenic bladder, Neurogenic lower urinary tract dysfunction, Detrusor sphincter dyssynergia, Sacral nerve stimulation Pudendal nerve stimulation, Spinal cord injuries

\section{Introduction}

The lower urinary tract (LUT), including the urinary bladder, urethra, and periurethral striated muscles, serves two important roles: continence, the storage of urine in the bladder, and micturition, efficient voiding of urine from the bladder at an appropriate time. These functions are controlled by neural circuits in the spinal cord, brainstem, and higher centers, and engage the sympathetic (hypogastric nerve), parasympathetic (pelvic nerve), and somatic (pudendal nerve) nervous systems. ${ }^{1}$ The generalized neural and anatomical connections important in regulation of the LUT, drawn

Correspondence to: Warren M. Grill, Department of Biomedical Engineering, Duke University, 136 Hudson Hall, Box 90281, Durham, NC 27708-0281 USA. Email: warren.grill@duke.edu from both human and animal studies, are shown in Fig. 1. The bladder and urethral sphincter(s) are controlled in a reciprocal manner to accomplish the two primary functions of the LUT. During storage, urine is retained in the bladder because the sympathetic pathway is activated, producing bladder relaxation via adrenergic signaling through the hypogastric nerve, and activation of the somatic pudendal nerve output from Onuf's nucleus produces coordinated contraction of the external urethral sphincter (EUS). ${ }^{2}$ The initiation of voiding occurs when the parasympathetic pathway is activated, producing contraction of the detrusor muscle in the bladder via cholinergic excitation through the pelvic nerve and the urethral sphincters are relaxed, allowing urine to leave the bladder and flow through the urethra. ${ }^{3,4}$ 


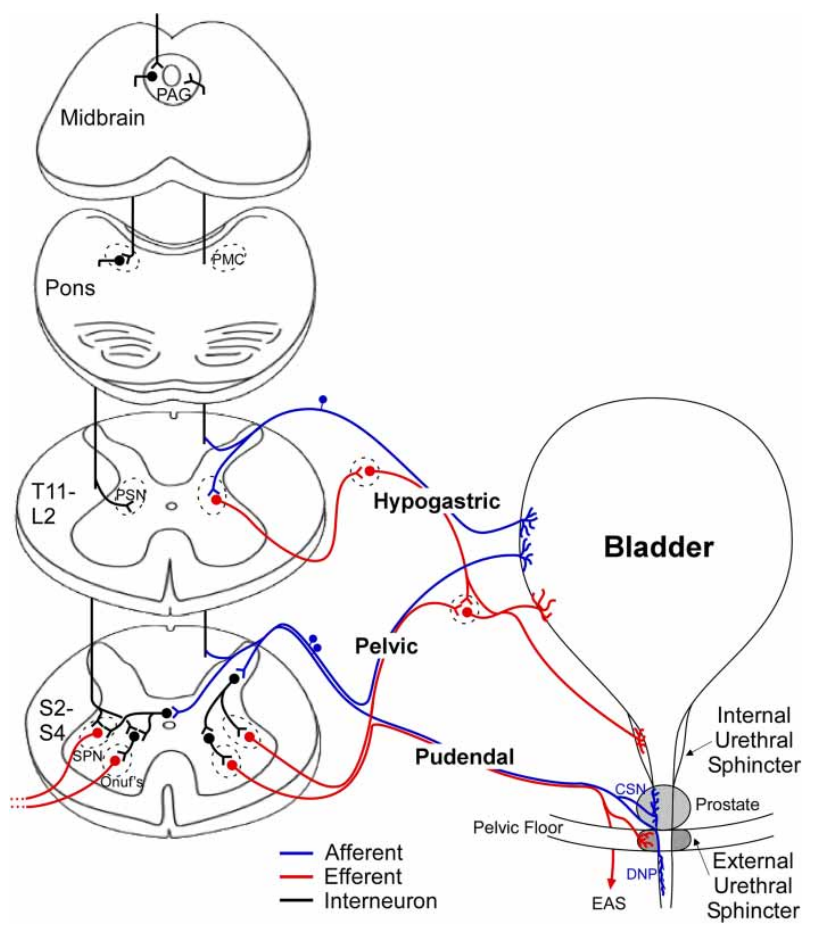

Figure 1 Neural and anatomical connections of normal lower urinary tract control. Afferents from the bladder and pelvic floor enter the spinal cord at the thoracic and sacral levels where they send ascending projections or synapse with local neurons. Descending modulation from the periaqueductal gray (PAG) and pontine micturition center (PMC) coordinates bladder and sphincter activity by controlling the output of the preganglionic sympathetic nucleus (PSN), sacral parasympathetic nucleus (SPN), and Onuf's nucleus. Abbreviations: cranial sensory nerve (CSN), dorsal nerve of the penis (DNP), external anal sphincter (EAS).

During bladder filling, afferent fibers in the pelvic and hypogastric nerves deliver information from mechanoreceptors sensitive to pressure and stretch, or increases in tension of the bladder wall, signaling bladder distention to the sacral and lumbar levels of the spinal cord, respectively. ${ }^{5-7}$ The pudendal nerve (PN) also contains afferent nerves; the dorsal genital nerve (dorsal nerve of the penis - DNP) is well documented in humans, and other smaller sensory branches have been identified in animals, such as the cranial sensory nerve (CSN) in cats. ${ }^{8}$ These somatic fibers provide sensory input from the pelvic floor, urethra, and external genitalia to the sacral spinal cord and play a role in mediating pudendo-vesical reflexes ${ }^{9}$ that can impact continence and micturition by providing negative (guarding reflex $)^{10}$ or positive feedback (augmenting reflex) during urine flow in the urethra ${ }^{11,12}$ (Fig. 1). After entering the dorsal horn, the afferents diverge; some fibers make projections in the dorsal horn to local interneurons and some send long ascending projections to the periaqueductal gray (PAG) and pontine micturition center (PMC). ${ }^{13}$

The PMC plays a critical role in the regulation of continence and micturition, and switching circuitry located between the PAG and PMC integrates the ascending afferent signals and descending commands from higher brain centers to direct the transition from continence to micturition that is executed by the PMC. ${ }^{14,15}$ Chemical or electrical stimulation of the PMC produces voiding that is very similar to reflex micturition, ${ }^{16}$ indicating that the PMC is a critical center for micturition. Descending signals from the PMC produce excitation of the sacral parasympathetic nucleus (SPN), causing bladder excitation and an increase in bladder pressure, and inhibition of Onuf's nucleus (the pudendal motor nucleus) to produce relaxation of the external urethral sphincter (EUS), allowing urine to flow. ${ }^{5}$

Spinal cord injury (SCI) interrupts normal control of bladder function by blocking both the transmission of afferent information to the PAG and PMC and efferent commands to lower spinal levels which modulate the output nuclei of the LUT. ${ }^{17}$ Without these pathways intact, aberrant reflexes can develop below the spinal cord lesion to produce uncoordinated LUT activity, leading to incontinence and/or urinary retention.

In normal bladder function, spinal reflexes that do not involve the PMC or PAG are well established. For example, the guarding reflex can be initiated by sensory activation of the pudendal nerve following EUS contraction or unexpected urine flow, which inhibits preganglionic sympathetic bladder neurons directly through spinal interneurons and produces continence. ${ }^{18}$ Normal pelvic-to-pudendal reflexes can be elicited by a rapid increase in bladder pressure and pelvic afferent activity, leading to increase in pudendal motor output which further contracts the EUS in order to maintain continence. ${ }^{19}$ In cases of LUT dysfunction following SCI, these reflexes may be disrupted, producing undesired contraction of the sphincters, i.e., detrusor-sphincter dyssynergia (DSD). However, lumbosacral spinal mechanisms that remain intact following SCI provide an opportunity for intervention for the restoration of LUT function.

In this review we discuss neurogenic lower urinary tract dysfunction (NLUTD) following spinal cord injury and the development of electrical stimulation as an approach to restore bladder function, including both continence and micturition. Applications of electrical stimulation for control of bladder function following SCI are discussed, spanning from historic clinical approaches to recent pre-clinical studies that may 
improve the success of electrical stimulation therapy in SCI patients.

\section{Bladder dysfunction after SCI}

Neurological disease and injury can cause significant disruption of both the storage and emptying functions of the LUT. SCI, specifically, causes LUT dysfunction characterized by neurogenic detrusor overactivity, urinary incontinence, chronic urinary retention (impaired micturition), and DSD. ${ }^{20}$ The location and severity of the SCI affect the degree of bladder dysfunction, from interrupting the communication between sacral and pontine micturition centers, to directly damaging the lumbosacral circuits that control the detrusor and pudendal nerve output. ${ }^{21}$ Spinal cord injuries are classified on a scale by the American Spinal Injury Association (ASIA), where A describes complete spinal transection where no sensory or motor function is preserved and $\mathrm{E}$ describes normal spinal cord function. ${ }^{22}$ Bladder dysfunction leads to substantial decreases in quality of life $^{23}$ and can cause urinary tract infections, skin breakdown, bladder and kidney damage, and re-hospitalization. ${ }^{24,25}$ Further, bladder dysfunction caused by SCI may change over the course of the injury, ${ }^{21}$ for example changing from an areflexic to an overactive bladder with time following injury, ${ }^{26}$ making bladder management difficult.

Injury to the spinal cord above the lumbosacral level removes the voluntary control of micturition, leading initially to an areflexive bladder and complete urinary retention. However, this is followed by slow development of a sacral spinal reflex mediated by unmyelinated $\mathrm{C}$ fibers. This reflex responds to low volume filling and leads to neurogenic detrusor overactivity (NDO). In addition to NDO, high-level spinal cord injuries (upper motor neuron lesions above T12) are more likely to produce DSD although any cord injury above S2 can result in DSD. Concurrent contraction of the bladder and urethral sphincter (DSD) can limit urinary flow and cause urinary retention; as well, DSD can lead to elevated detrusor pressures, which can put the upper urinary tract at risk of degeneration. ${ }^{27}$ Autonomic dysreflexia can occur in SCI above T5 but has been reported in patients with lesions as low as T8. This occurs due to a splanchnic outflow from the sympathetic system emanating from $\mathrm{T} 5$ to $\mathrm{L} 2$ and the absence of inhibition as a result of SCI. Autonomic dysreflexia leads to an exaggerated reaction to any stimuli below the level of SCI such as rectal impaction or rapid bladder filling during a urodynamic test. Symptoms of autonomic dysreflexia include an increase in blood pressure, bradycardia, sweating and headache.
Treatment includes removal of the stimulant, i.e., drain the bladder or evacuate the rectum and possibly medical management of the blood pressure. High level SCI was found to increase the risk of autonomic dysreflexia in one study, ${ }^{28}$ while another found that $48 \%$ of patients with complete SCI (ASIA A) above T6 had documented episodes of autonomic dysreflexia. ${ }^{29}$

Lower level spinal cord injuries (at S2 and below) produce very different effects on bladder function. Injury to the lower motor neurons classically results in bladder areflexia and low bladder compliance due to damage to the spinal micturition circuits ${ }^{27}$ and poor urethral function due to loss of somatic innervation. This type of injury can result in a variety of symptoms, including urinary retention, urinary incontinence, and if low bladder compliance is present, deterioration of kidney function.

The goals of management of NLUTD, including $\mathrm{NDO}$, are protection of the upper urinary tract, improvement of urinary incontinence, restoration of LUT function, and improvement in quality of life. ${ }^{24}$

Typically, the first line of treatment for NDO includes a combination of anticholinergic drugs. Anticholinergic therapy is frequently prescribed at higher doses for NDO than in overactive bladder (OAB) and this can lead to increased incidence of side effects including dry mouth, blurred vision, constipation, and cognitive changes. ${ }^{30}$ Although beta-3 adrenoceptor agonists are used in $\mathrm{OAB}$, there is no evidence of effect in patients with NLUTD.

If DSD is present, alpha-blockers, e.g. tamsulosin, may be used to reduce outlet resistance. Baclofen, a skeletal muscle relaxant often used to treat lower extremity spasticity, can decrease spasticity in the pelvic floor muscles but is not typically used for urethral outlet obstruction. ${ }^{21,31}$ Intermittent catheterization (IC), on average 4-6 times per day, is the gold standard for patients who are unable to empty their bladder. ${ }^{30}$ Aseptic or clean IC are feasible alternatives to sterile IC and decrease the risk for urinary tract infection as well as decrease the risk of significant complications seen with indwelling transurethral or suprapubic cystostomy. ${ }^{30}$ Other methods may be used to initiate voiding, such as bladder compression to expel urine (Credé), voiding by abdominal straining (Valsalva), and triggered reflex voiding. These maneuvers should be avoided in those with DSD as they create high pressures and are potentially hazardous to the upper tracts. ${ }^{21,32}$

If anticholinergic medications prove to be ineffective or poorly tolerated, botulinum toxin type-A injections in the bladder wall are the most effective minimally invasive treatment at this time to reduce NDO. ${ }^{30}$ The 
vanilloids, capsaicin and resiniferatoxin, are intravesical treatments that desensitize $\mathrm{C}$-fibers but have limited clinical efficacy compared to botulinum toxin type-A injections into the detrusor. ${ }^{33}$ For patients with DSD, minimally invasive procedures such as sphincterotomy ${ }^{34}$ or chemical deefferentiation of the sphincter using botulinum toxin type- $\mathrm{A}^{35}$ can be used to reduce bladder outlet resistance. When these less invasive procedures have failed, surgical procedures such as bladder augmentation, posterior rhizotomy with or without sacral anterior root stimulation (SARS) (complete lesions) and neuromodulation (incomplete lesions) are tried. Continent or incontinent diversion is indicated for small, contracted, noncompliant bladders.

\section{Clinical applications of electrical stimulation for bladder control}

Different locations have been investigated for application of electrical stimulation to restore functional bladder control, each with varying degrees of success. In the past, electrodes for stimulation to modulate bladder function have been placed on the bladder, skin, peripheral nerves, sacral roots, or spinal cord. ${ }^{36}$ Fig. 2 depicts the neural innervation of the lower urinary tract and common electrode locations for restoration of bladder control. The effectiveness of recently developed applications of electrical stimulation for bladder control has been evaluated in clinical studies in persons with $\mathrm{SCI},{ }^{37-40}$ although not in randomized, controlled clinical trials. The associated morbidities in patients with SCI adds complexity to the understanding of how each approach might be used to treat NLUTD, and the optimal, or even suitable, therapy is likely to vary across individuals.

There has been limited clinical success with direct bladder wall stimulation due to problems with concomitant sphincter activation (DSD) caused by reflex activity evoked by activation of pelvic afferents in the bladder, pain, or device failure. ${ }^{41-43}$ Pelvic nerve stimulation, i.e. stimulation of the nerve supply to the bladder, was shown to produce bladder contractions in dogs, but also resulted in co-activation of urethral sphincters. ${ }^{44}$ Pelvic nerve stimulation requires lower amplitudes of stimulation than direct bladder wall stimulation but application in humans is limited due to the difficulty of electrode placement. ${ }^{45}$

Spinal cord stimulation, particularly intraspinal stimulation for bladder control, has shown promising results in animals. ${ }^{46-48}$ However, this technique has not advanced because it is highly invasive, has high complication rates, and it is not clear that it provides benefit over sacral root stimulation. ${ }^{49}$ Transcutaneous electrical

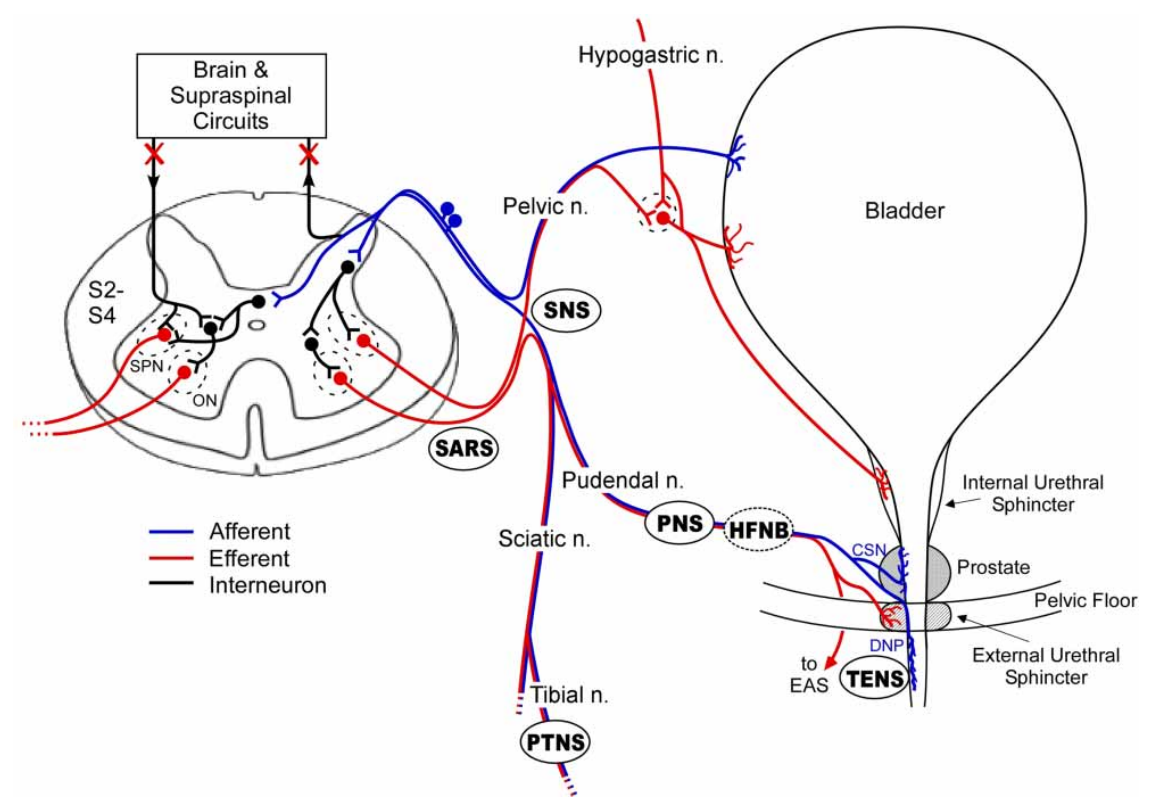

Figure 2 Locations targeted for restoration of bladder control using electrical stimulation. Anatomical locations of electrodes used for electrical stimulation for bladder function are shown: sacral anterior root stimulation (SARS), sacral nerve stimulation (SNS), pudendal nerve stimulation (PNS), percutaneous tibial nerve stimulation (PTNS), transcutaneous electrical nerve stimulation (TENS), and high frequency nerve block (HFNB). PNS, TENS, and PTNS can be performed with minimally invasive techniques. SARS typically requires a posterior rhizotomy. HFNB combined with PNS or SNS can eliminate unwanted contractions of the external urethral sphincter and produce efficient voiding. Following spinal cord injury (SCl), connections to the brain and higher order spinal circuits are lost. Abbreviations: cranial sensory neuron (CSN), dorsal nerve of the penis (DNP), Onuf's nucleus (ON), and sacral parasympathetic nucleus (SPN). 
stimulation for bladder control, e.g. surface stimulation of the dorsal nerve of the penis to inhibit bladder activity, targets peripheral nerves through a less invasive approach. But there are challenges of chronic clinical deployment at this location. The technology for electrical stimulation of the sacral roots and various peripheral nerves continues to evolve with promise for an effective neural prosthetic to restore NLUTD.

\section{Finetech-Brindley bladder control system}

Brindley and colleagues developed a system to allow bladder emptying with sacral anterior root stimulation $(\mathrm{SARS})^{50}$ that showed positive results in SCI patients. The Finetech-Brindley Bladder Control System (branded as VOCARE in the US) was granted a Humanitarian Device Exemption by the FDA in 1998 for bladder dysfunction in spinal cord injured patients. This system was the most successful electrical stimulation devices implanted for bladder control in SCI, increasing bladder capacity and allowing patients to void efficiently. ${ }^{39,51}$ However, the company that distributed VOCARE in the US, NeuroControl Corporation (Valley View, OH), went out of business in 2007.

The SARS system targets efferent nerve fibers emerging from the sacral spinal cord to produce bladder contraction $^{50}$ and provide efficient, on-demand voiding and a significant reduction in residual volumes and urinary tract infections, as well as bowel emptying. ${ }^{40,52}$ However, treatment of NDO and DSD required a concomitant posterior rhizotomy. Transection of the sacral dorsal roots (posterior rhizothomy) performed in combination with SARS to increase bladder capacity and compliance and improve voiding efficiency is effective, ${ }^{53}$ but irreversibly eliminates reflex erection, reflex micturition and any remaining pelvic sensation. ${ }^{36,54}$ Brindley reported that out of 12 of the early patients with reflex incontinence, all became fully continent following sacral posterior rhizotomies, and this is now standard practice with SARS implantation. ${ }^{55}$

In persons with supra-sacral SCI, SARS coupled with posterior rhizotomy produced voiding volumes greater than $200 \mathrm{~mL}$ in $18 / 21$ patients and decreased postvoid residual volumes below $50 \mathrm{~mL}$ in $15 / 21$ patients. ${ }^{39}$ SARS also substantially reduced the prevalence of urinary tract infections, reflex incontinence, autonomic dysreflexia, and decreased the frequency of catheterization and anticholinergic drug use in persons with SCI. ${ }^{39}$ Other studies report that SARS is safe and effective: 28 patients with SCI who were incontinent were completely dry after SARS with posterior rhizotomy. ${ }^{56}$ Further, this approach increased the quality of life of persons with $\mathrm{SCI},{ }^{57}$ and the cost of managing the neurogenic bladder and bowel after SCI was greatly reduced with SARS and posterior rhizotomy, compared to standard treatments. ${ }^{58}$

Although SARS is a very effective approach to restoring bladder control following SCI, through the year 2004 it was implanted in only approximately 2,500 people. ${ }^{59}$ The limited penetration may be due to the requirement of the irreversible posterior rhizotomy, the complexity of the implant surgery, as well as limited access at selected centers. In addition, the use of Botox and clean intermittent catheterization to manage LUT dysfunction after SCI may have decreased the demand for SARS. For those that are implanted and receive a posterior rhizotomy, bladder control with the device persists for many years. ${ }^{51,54,60}$

\section{Medtronic Interstim ${ }^{\circledR}$}

Sacral nerve stimulation (SNS) with the InterStim $^{\circledR}$ (Medtronic Inc., Minneapolis, MN, USA) was approved by the FDA in 1997 for urge urinary incontinence and in 1999 for urinary retention. ${ }^{59}$ SNS targets somatic afferent fibers entering the spinal cord and is thought to modulate the micturition reflex ${ }^{61}$ for treatment of urge urinary incontinence and urinary retention. ${ }^{59}$ Electrode implantation does not require laminectomy and is performed after a period of test stimulation with either a temporary percutaneous electrode or chronic lead placed in the S3 sacral foramen. Following this test period, device implantation occurs only in those patients who have $\geq 50 \%$ improvement in the LUTD symptoms. ${ }^{62}$ Long-term improvement of overactive bladder symptoms and urinary retention are achieved with SNS with Interstim ${ }^{\circledR}$, but these studies were all in non-SCI populations. ${ }^{63-67}$ Even in the nonneurogenic populations, success with InterStim $^{\circledR}$ is highly etiology-dependent, ${ }^{67,68}$ patients with urinary retention arising from specific electromyographic abnormalities of the EUS (i.e. Fowler's syndrome) were more likely to benefit from InterStim ${ }^{\circledR}$ than those from various etiologies. ${ }^{69}$

There has been limited study of Interstim ${ }^{\circledR}$ in SCI; however, in general, SNS has not been as effective in resolving symptoms of chronic urinary retention or incontinence in those with complete spinal cord lesions. ${ }^{70,71}$ In subjects with neurogenic bladder from complete SCI there was no significant difference in maximal bladder capacity, maximal detrusor pressure, or bladder volume at first uninhibited contraction with acute SNS. ${ }^{71}$ Additionally, one study reported that none of the 5 patients with complete SCI showed any improvement of their incontinence during the SNS test phase. $^{72}$ SNS may be more effective in incomplete 
SCI, and some studies show that the device improved continence by increasing cystometric capacity; persons with urinary retention from incomplete SCI saw a significant increase in urinary frequency and voided volume with SNS, while persons with urgency from incomplete SCI saw a significant decrease in the number of incontinent episodes and a significant increase in voided volume up to 5 years postimplant. ${ }^{38}$ In addition, the time before implant after SCI may influence the effectiveness of treatment, as early SNS in individuals with SCI prevented detrusor overactivity and urinary incontinence. ${ }^{73}$

\section{Percutaneous tibial nerve stimulation}

Peripheral nerves are an alternative stimulation target for bladder control following SCI. Stimulation of the tibial nerve, which originates from the L4-S3 lumbosacral plexus as part of the sciatic nerve, has been studied for treatment of OAB. Tibial nerve stimulation with the Urgent ${ }^{\circledR}$ PC Neuromodulation System (Uroplasty, Inc., Minnetonka, MN, USA) received FDA $510(\mathrm{k})$ clearance in 2007 for the treatment of urinary urgency, urinary frequency, and urge urinary incontinence. Percutaneous tibial nerve stimulation (PTNS) offers a less invasive treatment alternative to SNS, as surgical implantation is not required. PTNS is typically performed via a needle electrode inserted above the ankle. The procedure is office based and stimulation is delivered for 30 minutes once a week for 12 weeks. Randomized controlled studies report significant improvement with OAB symptoms ${ }^{74-76}$; however, only prospective non-randomized trials exist to support use in non-obstructive urinary retention ${ }^{77}$ and few studies have documented the effects of PTNS on NLUTD.

A study of PTNS for bladder dysfunction in 29 patients with various neurological lesions (including 15 patients with SCI) showed that $50 \%$ of the population had improvement in either maximum cystometric capacity or volume at first involuntary detrusor contraction. ${ }^{78}$ In a study of 70 multiple sclerosis patients, PTNS was well tolerated and produced clinical improvement of $\mathrm{OAB}$ symptoms in more than $82 \%$ of patients, ${ }^{79}$ suggesting that this therapy may be effective in SCI with incomplete lesions. In acute urodynamic tests, PTNS significantly increased maximum cystometric bladder capacity in patients with multiple sclerosis, indicating that PTNS may be an effective approach for clinical treatment of NDO ${ }^{80}$ In two persons with SCI, PTNS was used to treat successfully fecal incontinence up to 3 months follow up, pointing to the potential in other applications in SCI population. However, a recent study in animals found that bladder inhibition with PTNS was abolished following acute spinal cord transection, ${ }^{81}$ suggesting that PTNS employs supraspinal pathways and may not be suitable in persons with complete SCI.

\section{Pudendal nerve stimulation}

Stimulation of the pudendal nerve is another promising technique for the treatment of NLUTD following SCI. Mechanical activation of pudendal afferents, elicited by penile squeeze, inhibits the bladder and quiets existing bladder contractions. ${ }^{82}$ Recent clinical studies demonstrate that pudendal nerve stimulation (PNS) can produce both inhibition of bladder contractions, or at different stimulation parameters, bladder activation in persons with $\mathrm{SCI} .{ }^{37,83-89}$

The pudendal nerve is a somatic nerve in the pelvic region that originates from the sacral spinal cord at levels S2-S4 in humans. ${ }^{90}$ Access to the pudendal nerve for electrical stimulation can be made via a trans-gluteal incision ${ }^{91}$ or less-invasive percutaneous or transcutaneous approaches. ${ }^{85}$ PNS refers to electrical stimulation of the pudendal nerve, containing both sensory and motor fibers, or electrical stimulation applied to distal branches; for example, the dorsal genital nerve (DGN), a purely afferent branch that transmits sensory information from the urethra and external genitalia.

In one study comparing the effectiveness of SNS with Interstim $^{\circledR}$ to PNS in patients with OAB symptoms, the $\mathrm{PN}$ lead produced greater overall reduction in symptoms of urinary frequency and urgency and was chosen as the preferred lead by the majority of participants. ${ }^{92}$ PNS may be an alternative neuromodulation therapy for refractory $\mathrm{OAB}$, particularly in patients who do not respond well to SNS. ${ }^{93-95}$ However, although a CE mark has been granted in Europe, PNS remains for investigational use only in the United States. Studies are ongoing to evaluate the effectiveness of PNS for bladder control following SCI and to study novel stimulation paradigms for more effective treatment of NLUTD.

\section{Pre-clinical studies and future translational opportunities}

There is a need for development of methods that improve voiding efficiency and continence control for those with SCI without requiring a dorsal rhizotomy, and a better understanding of the underlying mechanisms of SNS and PNS to improve these therapies, and devise new approaches. Pre-clinical studies in animals 
provide the opportunity to investigate the potential impact of new techniques of stimulation.

\section{Pudendal nerve stimulation in $\mathrm{SCl}$ as an alternative to sacral nerve stimulation}

Peripheral nerve stimulation is an alternative approach to target similar reflexes as sacral nerve stimulation, potentially with more specificity. In contrast to PNS, which targets a particular nerve or nerve branch, SNS with Interstim ${ }^{\circledR}$ targets the entire sacral nerve. The use of this non-selective location results in non-specific stimulation of both afferent and efferent fibers. This ambiguity contributes to the lack of understanding of the mechanisms by which sacral nerve stimulation works and why it remains ineffective for treatment of NLUTD after complete SCI. Because SNS is effective for the treatment of non-neurogenic bladder dysfunction and less successful for patients with complete SCI, there is speculation that preserved supraspinal connections are necessary for the positive effects of SNS. ${ }^{72}$ Many studies have identified that the primary effects of PNS occur through activation of spinal reflexes, ${ }^{81,96}$ which remain intact following supra-sacral SCI. This mechanistic difference is further corroborated by studies where patients with SCI experienced better symptom improvement with PNS than SNS. ${ }^{92}$

Reflex bladder inhibition has been demonstrated by mechanical or transcutaneous electrical stimulation of the perigenital skin in rats, ${ }^{97-99}$ cats, ${ }^{100-105}$ and humans $^{82}$ and is produced by activation of pudendal afferents. Electrical stimulation of the PN or DGN with low frequencies $(5-10 \mathrm{~Hz})$ produces reflex bladder inhibition, promoting continence. ${ }^{106-108}$ Critical for application in SCI, this inhibition persists following spinal cord transection. ${ }^{103,105}$ Additional work established the feasibility of closed-loop continence control. ${ }^{109}$ Conditional PNS, triggered by pudendal nerve activity recorded by electroneurogram, was more effective at inhibiting the onset of bladder contractions than continuous stimulation. ${ }^{108}$ In patients with SCI, increased bladder capacity and decreased storage pressures were produced by event-driven electrical stimulation of the dorsal penile or clitoral nerve triggered by increases in either $\mathrm{EMG}^{110}$ or bladder pressure. ${ }^{111}$

While low frequency stimulation of pudendal afferents produces reflex bladder inhibition, high frequency stimulation $(20-50 \mathrm{~Hz})$ produces bladder excitation in cats ${ }^{103,106}$ and rats. ${ }^{12,113}$ High frequency stimulation can be used to augment existing bladder contractions or produce robust bladder contractions and voiding when desired ${ }^{114}$; in many cases contraction can be evoked at lower bladder volumes than distension- evoked activity. ${ }^{115}$ Voiding with intermittent PN stimulation was more effective than distension-evoked voiding or voiding produced by intermittent sacral root stimulation in anesthetized cats and was not limited by stimulation induced bladder-sphincter dyssynergia. ${ }^{116}$ Reflex bladder activation with high frequency stimulation of the pudendal nerve has also been demonstrated in humans with SCI. ${ }^{37}$ The use of pudendal afferent stimulation to produce both bladder inhibition, for continence control, and bladder activation, necessary for efficient voiding, in humans following SCI, ${ }^{103,105,107}$ further demonstrates the potential of this approach for the treatment of bladder dysfunction following SCI.

More recent studies differentiated the distal PN branches and evaluated the effects of stimulation of individual nerve branches on activation and inhibition of the bladder. $^{8,114}$ Selective stimulation of afferent branches of the PN reduced or eliminated activation of efferent pathways to the EUS, ${ }^{114,117}$ which would otherwise be undesirable for efficient voiding. Selective co-stimulation of PN afferents in multiple sensory branches or bilateral stimulation of DNP evoked significantly larger bladder contractions and improved voiding over individual branch stimulation in cats. ${ }^{118}$ Intraurethral electrical stimulation to target the distal branches of the PN produced similar frequency tuning responses to low and high frequency stimulation in cats $^{85,96}$ and evoked bladder contractions in humans with SCI. $^{119}$

A study of the fascicular anatomy and surgical access of the pudendal nerve in humans found that placement of a nerve cuff on the PN is both anatomically and surgically feasible. ${ }^{91}$ This approach could be employed for use with multi-electrode nerve cuffs for selective stimulation of specific fascicles within the pudendal nerve, ${ }^{120}$ to eliminate dyssynergia produced by direct stimulation or reflex activation of motor fibers innervating the EUS.

Experiments performed in cats further investigated the effects of temporal pattern of stimulation on reflex bladder activation. Variable patterned stimulation resulted in larger evoked reflex bladder contractions and demonstrated an increase in the range of parameters that caused bladder contraction. ${ }^{121}$ Specifically, bursting patterns of stimulation delivered to the pudendal nerve $^{121}$ or in the proximal urethra via intraurethral stimulation $^{122,123}$ improved bladder excitation and voiding in cats. These animal experiments illustrate the importance of further identification the mechanisms of PNS to produce efficient and effective bladder control following SCI. 
Nerve blocking with electrical signals

Application of high frequency (in the $\mathrm{kHz}$ range) signals to the PN can block the motor axons to the urethral sphincter and thereby mitigate the effects of DSD. ${ }^{124-126}$ Blockade of neural signals with kilohertz frequency stimulation could be used to improve voiding by blocking dyssynergic activity in the $\mathrm{PN}$ or efferent activity produced by stimulation of the sacral roots or PN. ${ }^{127}$ This method was inspired by earlier experiments with high frequency stimulation of the PN that produced bladder emptying similar to posterior rhizotomy in chronic SCI dogs, due to EUS fatigue from depletion of the neuromuscular junction following stimulation. ${ }^{128}$

High frequency block of the PN coupled with stimulation of sacral nerve or proximal PN in animals produced significant improvements in voiding efficiency compared to sacral nerve stimulation alone. ${ }^{127,129}$ High frequency block of the PN can also be used to reduce EUS spasticity, avoiding the need for a posterior rhizotomy, or be used to reversibly block EUS contractions during bladder contractions to improve voiding ${ }^{127}$ High frequency block was well tolerated in chronically implanted animals without anesthesia, ${ }^{126}$ demonstrating the possible clinical potential of this approach. However, although kilohertz frequency nerve block does not produce acute nerve damage, ${ }^{124,130}$ the safety and durability of chronic high frequency nerve block remain to be determined. ${ }^{131}$

\section{Coupling neuromodulation and pharmacological therapy for improved treatment}

Given that a large number of neurochemicals mediate bladder control by electrical stimulation, it is possible that pharmacological interventions could augment the effects of electrical stimulation. However, successful development and optimization of new therapeutic approaches requires understanding the underlying mechanisms of action of electrical stimulation.

Bladder inhibition with low frequency PNS was preserved following hypogastric nerve transection and administration of $\alpha$ - and $\beta$-adrenergic antagonists, ${ }^{115}$ and recent work demonstrates that this inhibition is mediated by GABAergic activity in the lumbosacral spinal cord. ${ }^{132}$ Opioids were also found to contribute to the inhibitory pudendal-to-bladder reflex in cats. ${ }^{133}$ In similar experiments, opioids were found to play a differential role in inhibition of nociceptive and non-nociceptive bladder contractions by tibial nerve stimulation. ${ }^{134}$ Other experiments have demonstrated that metabotropic glutamate 5 receptors, ${ }^{135,136}$ and serotoninergic receptors, ${ }^{137}$ which may interact with opioid mechanisms, are involved in bladder inhibition by PNS and that the effects are primarily mediated by spinal, not supraspinal, processes. ${ }^{81}$ Convergence of pudendal and pelvic afferents to increase pelvic efferent activity at the sacral level is likely responsible for bladder excitation with PNS. ${ }^{115}$ A combination of electrical stimulation and pharmacological treatment may improve treatment of bladder dysfunction in persons with SCI; for example, coupling electrical stimulation for bladder inhibition and $\alpha$-adrenoreceptor antagonists may improve continence by increasing bladder capacity. ${ }^{138}$ Intrathecal baclofen, a $\mathrm{GABA}_{\mathrm{B}}$ agonist, has been used to treat urethral sphincter spasticity ${ }^{139}$ and could be coupled with electrical stimulation to reduce NDO and urinary incontinence. Intrathecal administration of opioid agonists inhibited contractions and reduced DSD in spinal cord injured animal studies and could be used to boost the effects of bladder inhibition with PNS. ${ }^{140}$ Lastly, benzodiazepines, acting as an agonist of the effects of $\mathrm{GABA}_{\mathrm{A}}$, could enhance the effects of $\mathrm{GABA}_{\mathrm{A}}$-mediated PNS bladder inhibition. ${ }^{132,141}$

\section{Conclusion}

Understanding the specific neural circuits and neurotransmitters involved will drive the development of new stimulation paradigms for NLUTD in SCI and reveal additional opportunities for pharmacological intervention. Stimulation of the pudendal nerve is a promising approach to restore control of both continence and micturition in SCI, and continued work in this area will reveal how the effects of PNS compare to other stimulation modalities.

The selective stimulation of peripheral afferents may allow more precise control of bladder function, particularly with the selective stimulation of reflex pathways. Novel stimulation techniques, such as peripheral optogenetics, ${ }^{142,143}$ or the use of light to stimulate selectively genetically-targeted neurons, may enable improved control of bladder activity. Further development of novel applications of temporal patterns of stimulation, including high frequency conduction block, will drive progress towards additional therapies for bladder control following SCI. Additionally, peripheral nerves allow for electrode implantation via minimally invasive surgical approaches. The optimal solution for restoration of bladder control after SCI may encompass a combination of efficient, targeted electrical stimulation, possibly at multiple locations, and pharmacological treatment to enhance symptom control.

\section{Disclaimer statements}

Contributors MJM and WMG conceived and designed the review. MJM wrote the article. CLA wrote part of 
the article and both CLA and WMG revised the completed manuscript.

Conflicts of interest The authors have no conflicts of interest to report.

Ethics approval None required.

Funding National Institutes of Health.

\section{References}

1 Beckel JM, Holstege G. Neurophysiology of the lower urinary tract. In: Andersson K-E, Michel MC, (eds.) Urinary Tract: Volume 202 of Handbook of Experimental Pharmacology. Berlin: Springer Berlin Heidelberg; 2011. p. 149-69.

2 de Groat WC. Integrative control of the lower urinary tract: preclinical perspective. Br J Pharmacol 2006;147(Suppl 2):S25-40.

3 Andersson K-E, Arner A. Urinary bladder contraction and relaxation: physiology and pathophysiology. Physiol Rev 2004;84(3): 935-86.

4 Beckel JM, Holstege G. Neuroanatomy of the Lower Urinary Tract. In: Andersson K-E, Michel MC, (eds.) Urinary Tract: Volume 202 of Handbook of Experimental Pharmacology. Berlin: Springer Berlin Heidelberg; 2011. p. 99-116.

5 Fowler CJ, Griffiths D, de Groat WC. The neural control of micturition. Nature reviews. Neuroscience 2008;9(6):453-66.

6 Shea VK, Cai R, Crepps B, Mason JL, Perl ER. Sensory fibers of the pelvic nerve innervating the rat's urinary bladder. J Neurophysiol 2000;84(4):1924-33.

7 Janig W, Morrison JF. Functional properties of spinal visceral afferents supplying abdominal and pelvic organs, with special emphasis on visceral nociception. Prog Brain Res 1986;67: 87-114.

8 Yoo P, Woock J, Grill W. Somatic innervation of the feline lower urinary tract. Brain Res 2008;1246:80-7.

9 Barrington FJ. The component reflexes of micturition in the cat. Brain 1931;54(2):177-88.

10 Mahony DT, Laferte RO, Blais DJ. Integral storage and voiding reflexes. Neurophysiologic concept of continence and micturition. Urology 1977;9(1):95-106.

11 Shafik A, Shafik AA, El-Sibai O, Ahmed I. Role of positive urethrovesical feedback in vesical evacuation. The concept of a second micturition reflex: the urethrovesical reflex. World $\mathrm{J}$ Urol 2003;21(3):167-70.

12 Shefchyk SJ, Buss RR. Urethral pudendal afferent-evoked bladder and sphincter reflexes in decerebrate and acute spinal cats. Neurosci Lett 1998;244(3):137-40.

13 Benarroch EE. Neural control of the bladder. Neurol 2010; 75(20):1839-46.

14 Griffiths DJ, Fowler CJ. The micturition switch and its forebrain influences. Acta Physiologica 2013;207(1):93-109.

15 de Groat WC, Wickens C. Organization of the neural switching circuitry underlying reflex micturition. Acta Physiologica 2013; 207(1):66-84.

16 Sugaya K, Matsuyama K, Takakusaki K, Mori S. Electrical and chemical stimulations of the pontine micturition center. Neurosci Lett 1987;80(2):197-201.

17 Morgan CW, de Groat WC, Felkins LA, Zhang SJ. Axon collaterals indicate broad intraspinal role for sacral preganglionic neurons. Proc Natl Acad Sci USA 1991;88(15):6888-92.

18 Park J, Bloom D, McGuire E. The guarding reflex revisited. Br J Urol 1997;80(6):940-5.

19 Lin T-B. Tetanization-induced pelvic-to-pudendal reflex plasticity in anesthetized rats. Am J Physiol Renal Physiol 2004;287(2): F245-F51.

20 Abrams P, Cardozo L, Fall M, Griffiths D, Rosier P, Ulmsten U, et al. The standardisation of terminology of lower urinary tract function: Report from the standardisation sub-committee of the International Continence Society. Neurourol Urodyn 2002; 21(2):167-78.
21 Benevento BT, Sipski ML. Neurogenic bladder, neurogenic bowel, and sexual dysfunction in people with spinal cord injury. Phys Ther 2002;82(6):601-12.

22 Kirshblum SC, Burns SP, Biering-Sorensen F, Donovan W, Graves DE, Jha A, et al. International standards for neurological classification of spinal cord injury (revised 2011). J Spinal Cord Med 2011;34(6):535-46.

23 Anderson KD. Targeting recovery: priorities of the spinal cord-injured population. J Neurotrauma 2004;21(10):1371-83.

$24 \mathrm{Ku} \mathrm{JH}$. The management of neurogenic bladder and quality of life in spinal cord injury. BJU International 2006; 98(4):739-45.

25 Van Kerrebroeck PEV, Koldewijn EL, Scherpenhuizen S, Debruyne FMJ. The morbidity due to lower urinary tract function in spinal cord injury patients. Paraplegia 1993;31(5): $320-9$.

26 Cruz CD, Cruz F. Spinal cord injury and bladder dysfunction: new ideas about an old problem. Sci World J 2011;11:214-34.

27 Weld KJ, Dmochowski RR. Association of level of injury and bladder behavior in patients with post-traumatic spinal cord injury. Urology 2000;55(4):490-4.

28 Helkowski WM, Ditunno JF, Boninger M. Autonomic dysreflexia: incidence in persons with neurologically complete and incomplete tetraplegia. J Spinal Cord Med 2003;26(3):244-7.

29 Lindan R, Joiner E, Freehafer AA, Hazel C. Incidence and clinical features of autonomic dysreflexia in patients with spinal cord injury. Paraplegia 1980;18(5):285-92.

30 Pannek J, Blok B, Castro-Diaz D, Del Popolo G, Kramer G, Radziszewski $\mathrm{P}$, et al. Guidelines on Neurogenic Lower Urinary Tract Dysfunction, Eur Urol. Arnhem, The Netherlands; 2013.

31 Burns AS, Rivas DA, Ditunno JF. The management of neurogenic bladder and sexual dysfunction after spinal cord injury. Spine 2001;26(24S):S129-S36.

32 Weld KJ, Graney MJ, Dmochowski RR. Clinical significance of detrusor sphincter dyssynergia type in patients with post-traumatic spinal cord injury. Urology 2000;56(4):565-8.

33 Cruz F, Dinis P. Resiniferatoxin and botulinum toxin type A for treatment of lower urinary tract symptoms. Neurourol Urodyn 2007;26(6 Suppl):920-7.

34 Reynard JM, Vass J, Sullivan ME, Mamas M. Sphincterotomy and the treatment of detrusor-sphincter dyssynergia: current status, future prospects. Spinal Cord 2003;41(1):1-11.

35 Dykstra DD, Sidi AA. Treatment of detrusor-sphincter dyssynergia with botulinum A toxin: a double-blind study. Arch Phys Med Rehabil 1990;71(1):24-6.

36 Gaunt RA, Prochazka A. Control of urinary bladder function with devices: successes and failures. In: Lynne CW, Canio P, (eds.) Prog Brain Res. London: Elsevier; 2006. Vol. 152, p. 163-94.

37 Yoo P, Klein S, Grafstein N, Horvath E, Amundsen C, Webster $\mathrm{G}$, et al. Pudendal nerve stimulation evokes reflex bladder contractions in persons with chronic spinal cord injury. Neurourol Urodyn 2007;26(7):1020-3.

38 Lombardi G, Del Popolo G. Clinical outcome of sacral neuromodulation in incomplete spinal cord injured patients suffering from neurogenic lower urinary tract symptoms. Spinal Cord 2009;47(6):486-91.

39 Creasey GH, Grill JH, Korsten M, U HS, Betz R, Anderson R, et al. An implantable neuroprosthesis for restoring bladder and bowel control to patients with spinal cord injuries: A multicenter trial. Arch Phys Med Rehabil 2001;82(11):1512-9.

40 Van Kerrebroeck PEV, Koldewijn EL, Rosier PFWM, Wijkstra H, Debruyne FMJ. Results of the treatment of neurogenic bladder dysfunction in spinal cord injury by sacral posterior root rhizotomy and anterior sacral root stimulation. J Urol 1996;155(4):1378-81.

41 Bradley WE, Chou SN, French LA. Further experience with the radio transmitter receiver unit for the neurogenic bladders. $\mathrm{J}$ Neurosurg 1963;20(11):953-60.

42 Hald T, Meier W, Khalili A, Agrawal G, Benton J, Kantrowitz A. Clinical experience with a radio-linked bladder stimulator. J Urol 1967;97(1):73-8.

43 Stenberg CC, Burnette HW, Bunts RC. Electrical stimulation of human neurogenic bladders: experience with 4 patients. J Urol 1967;97(1):79-84. 
44 Holmquist B, Olin T. Electromicturition in male dogs at pelvic nerve stimulation. An urethrocystographic study. Scand J Urol Nephrol 1968;2(2):115-27.

45 Hald T. Neurogenic dysfunction of the urinary bladder. An experimental and clinical study with special reference to the ability of electrical stimulation to establish voluntary micturition. Dan Med Bull 1969;16(Suppl 5):1+.

46 Pikov V, Bullara L, McCreery DB. Intraspinal stimulation for bladder voiding in cats before and after chronic spinal cord injury. J Neural Eng 2007;4(4):356.

47 Grill WM, Bhadra N, Wang B. Bladder and urethral pressures evoked by microstimulation of the sacral spinal cord in cats. Brain Res 1999;836(1):19-30.

48 Tai C, Booth AM, de Groat WC, Roppolo JR. Bladder and urethral sphincter responses evoked by microstimulation of $\mathrm{S} 2$ sacral spinal cord in spinal cord intact and chronic spinal cord injured cats. Exp Neurol 2004;190(1):171-83.

49 Nashold BS, Friedman H, Grimes J. Electrical stimulation of the conus medullaris to control the bladder in the paraplegic patient. Stereotact Funct Neurosurg 1981;44(4):225-32.

50 Brindley GS. An implant to empty the bladder or close the urethra. J Neurol Neurosurg Psychiatry 1977;40(4):358-69.

51 Van Kerrebroeck P, Koldewijn EL, Debruyne FMJ. Worldwide experience with the Finetech-Brindley sacral anterior root stimulator. Neurourol Urodyn 1993;12(5):497-503.

52 Vallès M, Rodríguez A, Borau A, Mearin F. Effect of sacral anterior root stimulator on bowel dysfunction in patients with spinal cord injury. Dis Colon Rectum 2009;52(5):986-92.

53 Krasmik D, Krebs J, van Ophoven A, Pannek J. Urodynamic results, clinical efficacy, and complication rates of sacral intradural deafferentation and sacral anterior root stimulation in patients with neurogenic lower urinary tract dysfunction resulting from complete spinal cord injury. Neurourol Urodyn 2014;33(8): 1202-6.

54 Brindley GS. The first 500 patients with sacral anterior root stimulator implants: general description. Paraplegia 1994; 32(12):795-805.

55 Brindley GS. The ferrier lecture, 1986: the actions of parasympathetic and sympathetic nerves in human micturition, erection and seminal emission, and their restoration in paraplegic patients by implanted electrical stimulators. Proc Royal Soc London Series B Biol Sci 1988;235(1279):111-20.

56 Madersbacher H, Fischer J. Sacral anterior root stimulation: Prerequisites and indications. Neurourol Urodyn 1993;12(5): 489-94.

57 Vastenholt JM, Snoek GJ, Buschman HPJ, van der Aa HE, Alleman ERJ, Ijzerman MJ. A 7-year follow-up of sacral anterior root stimulation for bladder control in patients with a spinal cord injury: quality of life and users' experiences. Spinal Cord 2003; 41(7):397-402.

58 Creasey GH, Dahlberg JE. Economic consequences of an implanted neuroprosthesis for bladder and bowel management. Arch Phys Med Rehabil 2001;82(11):1520-5.

59 Rijkhoff NM. Neuroprostheses to treat neurogenic bladder dysfunction: current status and future perspectives. Childs Nerv Syst 2004;20(2):75-86.

60 Martens FMJ, Heesakkers JPFA. Clinical results of a brindley procedure: sacral anterior root stimulation in combination with a rhizotomy of the dorsal roots. Adv Urol 2011;2011:7.

61 Vodusek DB, Light JK, Libby JM. Detrusor inhibition induced by stimulation of pudendal nerve afferents. Neurourol Urodyn 1986;5(4):381-9.

62 Bosch JLHR, Groen J. Sacral nerve neuromodulation in the treatment of patients with refractory motor urge incontinence: Longterm results of a prospective longitudinal study. J Urol 2000; 163(4):1219-22.

63 Jonas U, Fowler CJ, Chancellor MB, Elhilali MM, Fall M, Gajewski JB, et al. Efficacy of sacral nerve stimulation for urinary retention: Results 18 months after implantation. J Urol 2001;165(1):15-9.

64 van Kerrebroeck PEV, van Voskuilen AC, Heesakkers JPFA, Lycklama á Nijholt AAB, Siegel S, Jonas U, et al. Results of sacral neuromodulation therapy for urinary voiding dysfunction: outcomes of a prospective, worldwide clinical study. J Urol 2007; 178(5):2029-34

65 Dasgupta R, Wiseman OJ, Kitchen N, Fowler CJ. Long-term results of sacral neuromodulation for women with urinary retention. BJU International 2004;94(3):335-7.

66 Schmidt RA, Jonas U, Oleson KA, Janknegt RA, Hassouna MM, Siegel SW, et al. Sacral nerve stimulation for treatment of refractory urinary urge incontinence. J Urol 1999;162(2):352-7.

67 Chaabane W, Guillotreau J, Castel-lacanal E, Abu-Anz S, De Boissezon X, Malavaud B, et al. Sacral neuromodulation for treating neurogenic bladder dysfunction: Clinical and urodynamic study. Neurourol Urodyn 2011;30(4):547-50.

68 Comiter CV. Sacral neuromodulation for the symptomatic treatment of refractory interstitial cystitis: a prospective study. J Urol 2003;169(4):1369-73.

69 De Ridder D, Ost D, Bruyninckx F. The presence of fowler's syndrome predicts successful long-term outcome of sacral nerve stimulation in women with urinary retention. Eur Urol 2007; 51(1):229-34.

70 Kessler TM, La Framboise D, Trelle S, Fowler CJ, Kiss G, Pannek J, et al. Sacral neuromodulation for neurogenic lower urinary tract dysfunction: systematic review and meta-analysis. Eur Urol 2010;58(6):865-74.

71 Chartier-Kastler EJ, Denys P, Chancellor MB, Haertig A, Bussel B, Richard F. Urodynamic monitoring during percutaneous sacral nerve neurostimulation in patients with neurogenic detrusor hyperreflexia. Neurourol Urodyn 2001;20(1):61-71.

72 Schurch B, Reilly I, Reitz A, Curt A. Electrophysiological recordings during the peripheral nerve evaluation (PNE) test in complete spinal cord injury patients. World J Urol 2003;20(6):319-22.

73 Sievert K-D, Amend B, Gakis G, Toomey P, Badke A, Kaps HP, et al. Early sacral neuromodulation prevents urinary incontinence after complete spinal cord injury. Ann Neurol 2010;67(1):74-84.

74 Peters KM, MacDiarmid SA, Wooldridge LS, Leong FC, Shobeiri SA, Rovner ES, et al. Randomized trial of percutaneous tibial nerve stimulation versus extended-release tolterodine: results from the overactive bladder innovative therapy trial. $\mathbf{J}$ Urol 2009;182(3):1055-61.

75 Finazzi-Agro E, Petta F, Sciobica F, Pasqualetti P, Musco S, Bove P. Percutaneous tibial nerve stimulation effects on detrusor overactivity incontinence are not due to a placebo effect: a randomized, double-blind, placebo controlled trial. J Urol 2010;184(5): 2001-6.

76 Staskin D, Peters K, MacDiarmid S, Shore N, de Groat W. Percutaneous tibial nerve stimulation: a clinically and cost effective addition to the overactive bladder algorithm of care. Curr Urol Rep 2012;13(5):327-34

77 Vandoninck V, van Balken MR, Finazzi Agr E, Petta F, Micali F, Heesakkers JPFA, et al. Posterior tibial nerve stimulation in the treatment of idiopathic nonobstructive voiding dysfunction. Urology 2003;61(3):567-72.

78 Amarenco G, Ismael SS, Even-Schneider A, Raibaut P, DemailleWlodyka S, Parratte B, et al. Urodynamic effect of acute transcutaneous posterior tibial nerve stimulation in overactive bladder. $\mathbf{J}$ Urol 2003;169(6):2210-5.

79 de Sèze M, Raibaut P, Gallien P, Even-Schneider A, Denys P, Bonniaud V, et al. Transcutaneous posterior tibial nerve stimulation for treatment of the overactive bladder syndrome in multiple sclerosis: Results of a multicenter prospective study. Neurourol Urodyn 2011;30(3):306-11.

80 Kabay SC, Yucel M, Kabay S. Acute Effect of Posterior Tibial Nerve Stimulation on Neurogenic Detrusor Overactivity in Patients with Multiple Sclerosis: Urodynamic Study. Urology 2008;71(4):641-5.

81 Xiao Z, Rogers MJ, Shen B, Wang J, Schwen Z, Roppolo JR, et al. Somatic modulation of spinal reflex bladder activity mediated by nociceptive bladder afferent nerve fibers in cats. Am J Physiol Renal Physiol 2014;307(6):F673-9.

82 Kondo A, Otani T, Takita T. Suppression of bladder instability by penile squeeze. Br J Urol 1982;54(4):360-2

83 Gustafson KJ, Creasey GH, Grill WM. A urethral afferent mediated excitatory bladder reflex exists in humans. Neurosci Lett 2004;360(1-2):9-12. 
84 Kirkham AP, Shah NC, Knight SL, Shah PJ, Craggs MD. The acute effects of continuous and conditional neuromodulation on the bladder in spinal cord injury. Spinal Cord 2001;39(8): $420-8$.

85 Gustafson KJ, Creasey GH, Grill WM. A catheter based method to activate urethral sensory nerve fibers. J Comp Neurol 2003; 170(1):126-9.

86 Wheeler J, Walter J, Zaszczurynski P. Bladder inhibition by penile nerve stimulation in spinal cord injury patients. J Urol 1992; 147(1):100-3.

87 Lee YH, Creasey GH, Lim H, Song J, Song K, Kim J. Detrusor and blood pressure responses to dorsal penile nerve stimulation during hyperreflexic contraction of the bladder in patients with cervical cord injury. Arch Phys Med Rehabil 2003;84(1):136-40.

88 Previnaire JG, Soler JM, Perrigot M, Boileau G, Delahaye H, Schumacker P, et al. Short-term effect of pudendal nerve electrical stimulation on detrusor hyperreflexia in spinal cord injury patients: importance of current strength. Paraplegia 1996;34(2): 95-9.

89 Vodušek DB, Plevnik S, Vrtačnik P, Janež J. Detrusor inhibition on selective pudendal nerve stimulation in the perineum. Neurourol Urodyn 1987;6(5):389-93.

90 Shafik A, El-Sherif M, Youssef A, Olfat E-S. Surgical anatomy of the pudendal nerve and its clinical implications. Clin Anat 1995; $8(2): 110-5$.

91 Gustafson K, Zelkovic P, Feng A, Draper C, Bodner D, Grill W. Fascicular anatomy and surgical access of the human pudendal nerve. World J Urol 2005;23(6):411-8.

92 Peters KM, Feber KM, Bennett RC. Sacral versus pudendal nerve stimulation for voiding dysfunction: a prospective, singleblinded, randomized, crossover trial. Neurourol Urodyn 2005; 24(7):643-7.

93 Mashni J, Peters K. Potential use of pudendal nerve stimulation for voiding dysfunction. Curr Bladder Dysfunct Rep 2010;5(4): $177-82$.

94 Sherman ND, Amundsen CL. Current and future techniques of neuromodulation for bladder dysfunction. Curr Urol Rep 2007; 8(6):448-54.

95 Peters KM, Killinger KA, Boguslawski BM, Boura JA. Chronic pudendal neuromodulation: Expanding available treatment options for refractory urologic symptoms. Neurourol Urodyn 2010;29(7):1267-71.

96 Woock J, Yoo P, Grill W. Intraurethral stimulation evokes bladder responses via two distinct reflex pathways. J Urol 2009;182(1): $366-73$.

97 Hotta H, Masunaga K, Miyazaki S, Watanabe N, Kasuya Y. A gentle mechanical skin stimulation technique for inhibition of micturition contractions of the urinary bladder. Auton Neurosci 2012;167(1-2):12-20.

98 Sato A, Sato Y, Shimada F, Torigata Y. Changes in vesical function produced by cutaneous stimulation in rats. Brain Res 1975; 94(3):465-74

99 Morrison JF, Sato A, Sato Y, Yamanishi T. The influence of afferent inputs from skin and viscera on the activity of the bladder and the skeletal muscle surrounding the urethra in the rat. Neurosci Res 1995;23(2):195-205.

100 Sato A, Sato Y, Sugimoto H, Terui N. Reflex changes in the urinary bladder after mechanical and thermal stimulation of the skin at various segmental levels in cats. Neurosci 1977;2(1):111-7.

101 Thor KB, Hisamitsu T, de Groat WC. Unmasking of a neonatal somatovesical reflex in adult cats by the serotonin autoreceptor agonist 5-methoxy-N,N-dimethyltryptamine. Brain Res Dev Brain Res 1990;54(1):35-42.

102 Wang J, Liu H, Shen B, Roppolo JR, De Groat WC, Tai C. Bladder inhibition or excitation by electrical perianal stimulation in a cat model of chronic spinal cord injury. BJU Int 2009;103(4): $530-6$.

103 Tai C, Wang J, Wang X, de Groat WC, Roppolo JR. Bladder inhibition or voiding induced by pudendal nerve stimulation in chronic spinal cord injured cats. Neurourol Urodyn 2007;26(4): $570-7$.

104 Tai C, Shen B, Wang J, Chancellor MB, Roppolo JR, de Groat WC. Inhibitory and excitatory perigenital-to-bladder spinal reflexes in the cat. Am J Physiol Renal Physiol 2008;294(3): F591-F602.

105 Tai C, Chen M, Shen B, Wang J, Liu H, Roppolo JR, et al. Plasticity of urinary bladder reflexes evoked by stimulation of pudendal afferent nerves after chronic spinal cord injury in cats. Exp Neurol 2011;228(1):109-17.

106 Boggs JW, Wenzel BJ, Gustafson KJ, Grill WM. Frequencydependent selection of reflexes by pudendal afferents in the cat. J Physiol 2006;577(1):115-26.

107 Tai C, Smerin SE, de Groat WC, Roppolo JR. Pudendal-tobladder reflex in chronic spinal-cord-injured cats. Exp Neurol 2006;197(1):225-34.

108 Wenzel BJ, Boggs JW, Gustafson KJ, Grill WM. Closed loop electrical control of urinary continence. J Urol 2006;175(4):1559-63.

109 Kirkham A, Shah N, Knight S, Shah P, Craggs M. The acute effects of continuous and conditional neuromodulation on the bladder in spinal cord injury. Spinal Cord 2001;39(8):420-8.

110 Dalmose AL, Rijkhoff NJM, Kirkeby HJ, Nohr M, Sinkjaer T, Djurhuus JC. Conditional stimulatzion of the dorsal penile/clitoral nerve may increase cystometric capacity in patients with spinal cord injury. Neurourol Urodyn 2003;22(2):130-7.

111 Hansen J, Media S, Nøhr M, Biering-Sørensen F, Sinkjaer T, Rijkhoff NJM. Treatment of neurogenic detrusor overactivity in spinal cord injured patients by conditional electrical stimulation. J Urol 2005;173(6):2035-9.

112 Peng C-W, Chen J-JJ, Cheng C-L, Grill WM. Role of pudendal afferents in voiding efficiency in the rat. Am J Physiol Regul Integr Comp Physiol 2008;294(2):R660-R72.

113 Peng CW, Chen JJ, Cheng CL, Grill WM. Improved bladder emptying in urinary retention by electrical stimulation of pudendal afferents. J Neural Eng 2008;5(2):144-54.

114 Woock J, Yoo P, Grill W. Activation and inhibition of the micturition reflex by penile afferents in the cat. Am J Physiol Regul Integr Comp Physiol 2008;294(6):R1880-9.

115 Woock JP, Yoo PB, Grill WM. Mechanisms of reflex bladder activation by pudendal afferents. Am J Physiol Regul Integr Comp Physiol 2011;300(2):R398-R407.

116 Boggs JW, et al. Bladder emptying by intermittent electrical stimulation of the pudendal nerve. J Neural Eng 2006;3(1):43.

117 Yoo PB, Woock JP, Grill WM. Bladder activation by selective stimulation of pudendal nerve afferents in the cat. Exp Neurol 2008;212(1):218-25.

118 McGee MJ, Grill WM. Selective co-stimulation of pudendal afferents enhances bladder activation and improves voiding efficiency. Neurourol Urodyn 2014;33(8):1272-8.

119 McGee MJ, Yoo PB, Grill WM editors. Selective co-stimulation of pudendal afferents enhances reflex bladder activation. EMBC, Ann Int Conf of the IEEE. Boston; 2011. p. 1057-60.

120 Kent AR, Grill WM. Model-based analysis and design of nerve cuff electrodes for restoring bladder function by selective stimulation of the pudendal nerve. J Neural Eng 2013;10(3):036010.

121 Bruns TM, Bhadra N, Gustafson KJ. Variable patterned pudendal nerve stimuli improves reflex bladder activation. IEEE Trans Rehabil Eng 2008;16(2):140-8.

122 Bruns TM, Bhadra N, Gustafson KJ. Bursting stimulation of proximal urethral afferents improves bladder pressures and voiding. J Neural Eng 2009;6(6):066006.

123 Bruns T, Bhadra N, Gustafson K. Intraurethral stimulation for reflex bladder activation depends on stimulation pattern and location. Neurourol Urodyn 2009;28(6):561-6.

124 Bhadra N, Kilgore K, Gustafson KJ. High frequency electrical conduction block of the pudendal nerve. J Neural Eng 2006; 3(2):180-7.

125 Tai C, Roppolo JR, de Groat WC. Block of external urethral sphincter contraction by high frequency electrical stimulation of pudendal nerve. J Urol 2004;172(5, Part 1):2069-72.

126 Gaunt RA, Prochazka A. Transcutaneously coupled, high-frequency electrical stimulation of the pudendal nerve blocks external urethral sphincter contractions. Neurorehabilitation and Neural Repair 2009;23(6):615-26.

127 Boger A, Bhadra N, Gustafson KJ. Bladder voiding by combined high frequency electrical pudendal nerve block and sacral root stimulation. Neurourol Urodyn 2008;27(5):435-9. 
128 Sawan M, Hassouna MM, Li J, Duval F, Elhilali MM. Stimulator design and subsequent stimulation parameter optimization for controlling micturition and reducing urethral resistance. IEEE Trans Rehabil Eng 1996;4(1):39-46.

129 Shaker HS, Tu LM, Robin S, Arabi K, Hassouna M, Sawan M, et al. Reduction of bladder outlet resistance by selective sacral root stimulation using high-frequency blockade in dogs: an acute study. J Urol 1998;160(3, Part 1):901-7.

130 Tai C, Roppolo JR, de Groat WC. Response of external urethral sphincter to high frequency biphasic electrical stimulation of pudendal nerve. J Urol 2005;174(2):782-6.

131 Franke M, Bhadra N, Bhadra N, Kilgore K. Direct current contamination of kilohertz frequency alternating current waveforms. Journal of neuroscience methods 2014;232(0): 74-83.

132 McGee MJ, Danziger ZC, Bamford JA, Grill WM. A spinal GABAergic mechanism is necessary for bladder inhibition by pudendal afferent stimulation. Am J Physiol Renal Physiol 2014;307(8):F921-30.

133 Chen ML, Shen B, Wang J, Liu H, Roppolo JR, de Groat WC, et al. Influence of naloxone on inhibitory pudendal-to-bladder reflex in cats. Exp Neurol 2010;224(1):282-91.

134 Tai C, Larson JA, Ogagan PD, Chen G, Shen B, Wang J, et al. Differential role of opioid receptors in tibial nerve inhibition of nociceptive and nonnociceptive bladder reflexes in cats. Am J Physiol Renal Physiol 2012;302(9):F1090-F7.

135 Larson JA, Ogagan PD, Chen G, Shen B, Wang J, Roppolo JR, et al. Involvement of metabotropic glutamate receptor 5 in pudendal inhibition of nociceptive bladder activity in cats. $\mathbf{J}$ Physiol 2011;589(Pt 23):5833-43.

136 Mally AD, Matsuta Y, Zhang F, Shen B, Wang J, Roppolo JR, et al. Role of opioid and metabotropic glutamate 5 receptors in pudendal inhibition of bladder overactivity in cats. J Urol 2013; 189(4):1574-9.

137 Matsuta Y, Schwen Z, Mally AD, Shen B, Wang J, Roppolo JR, et al. Effect of methysergide on pudendal inhibition of micturition reflex in cats. Exp Neurol 2013;247(0):250-8.

138 Andersson K.-E, Appell R, Cardozo L, Chapple C, Drutz H, Finkbeiner A, et al. The pharmacological treatment of urinary incontinence. BJU International 1999;84(9):923-47.

139 Nanninga J, Frost F, Penn R. Effect of intrathecal baclofen on bladder and sphincter function. J Urol 1989;142(1):101-5.

140 Yokoyama O, Mita E, Akino H, Tanase K, Ishida H, Namiki M. Roles of opiate in lower urinary tract dysfunction associated with spinal cord injury in rats. J Urol 2004;171(2, Part 1):963-7.

141 Xiao Z, Reese J, Schwen Z, Shen B, Wang J, Roppolo JR, et al. Role of spinal GABAA receptors in pudendal inhibition of nociceptive and nonnociceptive bladder reflexes in cats. Am J Physiol Renal Physiol 2014;306(7):F781-F9.

142 Towne C, Montgomery KL, Iyer SM, Deisseroth K, Delp SL. Optogenetic control of targeted peripheral axons in freely moving animals. PLoS ONE 2013;8(8):e72691.

143 Iyer SM, Montgomery KL, Towne C, Lee SY, Ramakrishnan C, Deisseroth $\mathrm{K}$, et al. Virally mediated optogenetic excitation and inhibition of pain in freely moving nontransgenic mice. Nat Biotech 2014;32(3):274-8. 